\title{
Mutilating Nose Injury by Softshell Turtle (labi-labi) Bite: A Rare Case
}

\author{
${ }^{1}$ Razak Ismail, ${ }^{2}$ Md Khir Abdullah, ${ }^{3}$ Noorizan Yahya, ${ }^{4}$ Thiaga Gobal
}

\begin{abstract}
This case report discusses a case of mutilating injury of the tip nose caused by a softshell turtle bite. The patient was an aborigine who earned a living by catching and selling softshell turtles (Dogania subplana). He was bitten by one while trying to catch it. This case depicts the nature of this softshell turtle, the injuries it can cause, and the procedures for the reconstruction of the patient's nose. Softshell turtle bites have practically never been reported. However, softshell turtle bites on the nose, as with typical animal-inflicted injuries to the same area, can be treated using the same principles of managing a possibly-contaminated nasal wound.
\end{abstract}

Keywords: Graft, Mutilating injury, Softshell turtle.

How to cite this article: Ismail R, Abdullah MK, Yahya N, Gobal T. Mutilating Nose Injury by Softshell Turtle (labi-labi) Bite: A Rare Case. Clin Rhinol An Int J 2018;11(1):29-31.

Source of support: Nil

Conflict of interest: None

\section{BACKGROUND}

Softshell turtle bites have practically never been reported (Fig. 1). However, softshell turtle bites on the nose, as with typical animal-inflicted injuries to the same area, can be treated using the same principles of managing a possibly contaminated nasal wound.

\section{CASE PRESENTATION}

This is a case of a 17-year-old aborigine male from Muar. To make a living, he catches and sells softshell turtles. While catching turtles one day, he slipped, resulting in a $10 \mathrm{~kg}$ turtle falling onto him and biting his nose. He was brought to the accident and emergency Department of Hospital, Muar within 1 hour for treatment.

On examination, he was in pain, but vital signs were stable. Examination of the nose revealed a loss of the

\footnotetext{
${ }^{1}$ Doctor, ${ }^{2}$ Specialist ENT, ${ }^{3}$ Specialist, ${ }^{4}$ Medical Officer

${ }^{1}$ Department of Otorhinolaryngology-Head and Neck Surgery, National Hospital Malaysia, Kuala Lumpur, Malaysia

${ }^{2-4}$ Department of Otorhinolaryngology, Hospital Pakar Sultanah Fatimah, Muar, Malaysia

Corresponding Author: Razak Ismail, Doctor, Department of Otorhinolaryngology-Head and Neck Surgery, National Hospital Malaysia, Kuala Lumpur, Malaysia, e-mail: mbbsrazak@ gmail.com
}

right ala and an extensive amount of soft tissues (Fig. 2). There was minimal bleeding, which was well-controlled. The patient was started on IV co-amoxiclav $1.2 \mathrm{~g}$ TDS and $0.5 \mathrm{~mL}$ tetanus toxoid IM stat. He later underwent a full-thickness skin graft (Fig. 3), which was taken from the right postauricular region.

The patient was kept in the ward for a couple of days for dressing and wound care. On a postoperative day 5, he was well enough to be discharged. Subsequent followup showed that he responded well to the graft (Fig. 4).

\section{DISCUSSION}

The Malayan softshell turtle (Dogania subplana) belongs to the family Trionychidae, and can mainly be found in

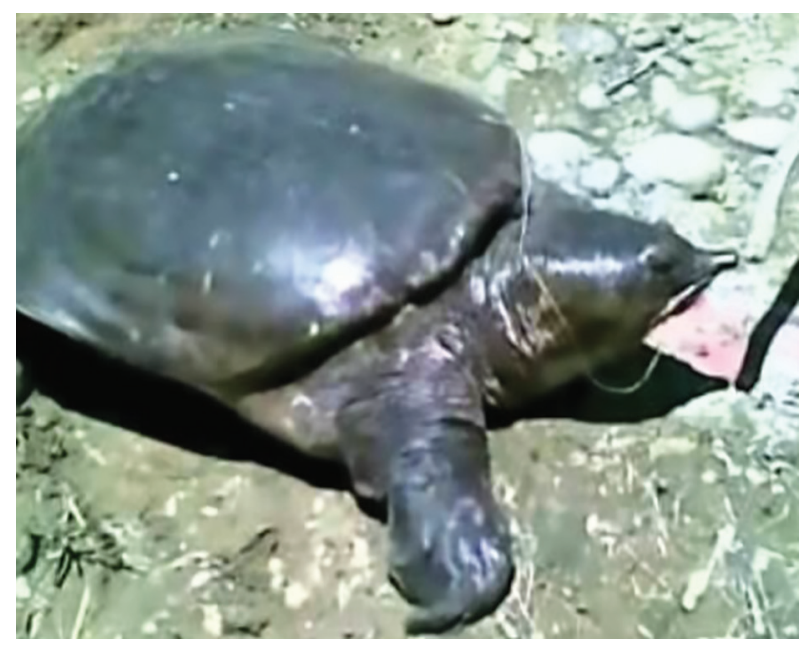

Fig. 1: Softshell turtle

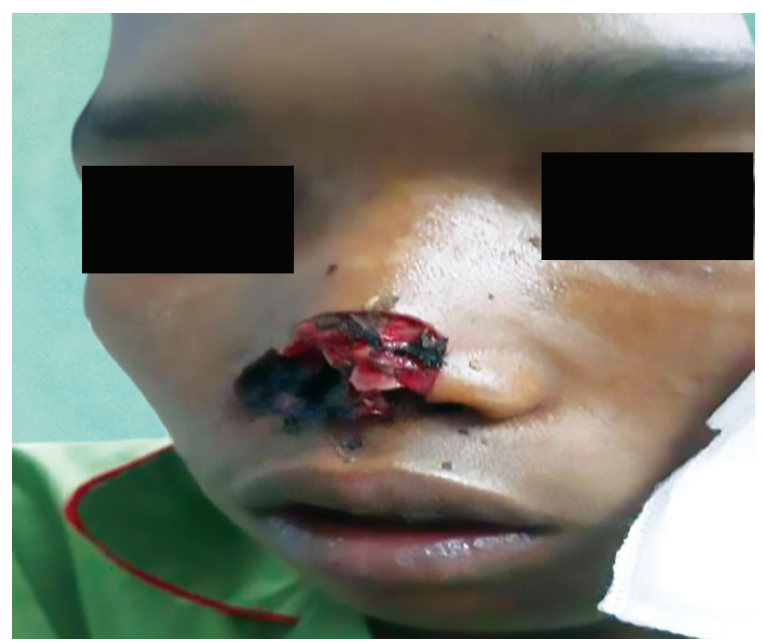

Fig. 2: A male aborigine with loss of right ala of nose 


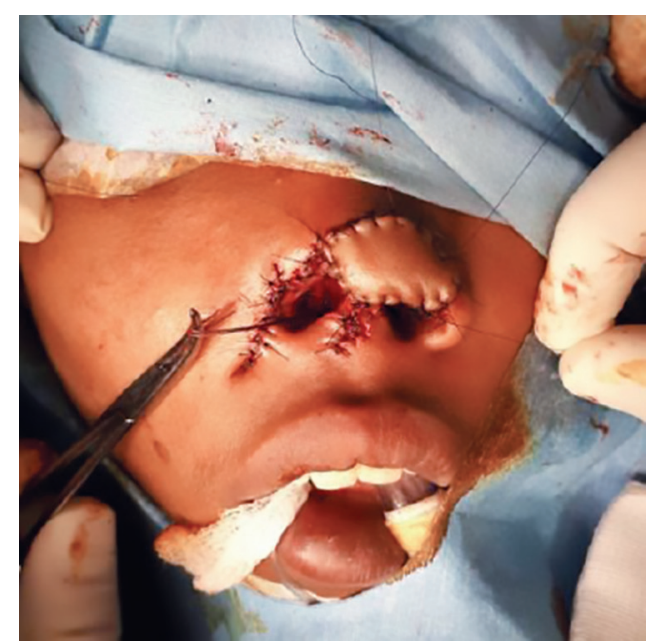

Fig. 3: Reconstruction with full-thickness skin graft

Southeast Asia. It is a reptile and resides in clean running water, usually in rocky streams at higher altitudes. With its powerful jaws, it is carnivorous, and its diet predominantly comprises snails as well as other mollusks. While the jaws are mainly used to crush the shells of the aforementioned animals, it can pose a danger to humans, although there are currently no reports of softshell turtle bites in the literature. Morphologically, Dogania subplana can grow-up to a length of $35 \mathrm{~cm}$. The head is large and muscular, while the carapace flat with straight sides. As with other members of the Trionychidae family, it has a long, tapering nose. Color-wise, the adults are brownishgreen, while the juveniles are reddish on the sides of the neck, with some round black spots on their carapaces (Fig. 1). ${ }^{1}$

While animal bite injuries are very common in Southeast Asia, mutilating injuries caused by animal bites are relatively rare. If the latter does happen to the face, there are risks of (a) complex injuries to the soft and hard tissues (which present as perforations, lacerations, crushes, avulsions, or fractures), as well as (b) infections due to the presence of copious bacteria and viruses in such injuries. ${ }^{2,3}$ In light of extensive blood supply to the face and scalp, infection rates are low (usually $<6 \%$ ). ${ }^{4,5}$ Many studies have reported that the frequency of wound infections was $<5 \%$, but a few have quoted higher values, with a maximum of $30 \%$. However, the effects of disfigurement usually remain, oftentimes with psychological scarring as well. $^{2}$

In all cases of animal-inflicted injuries to the face, advanced trauma life support (ATLS) should be done, especially cervical spine immobilization and neurological evaluation. This is because large animals can injure, crush, or shake the cranium, hence injuring the cervical spine. ${ }^{3,6}$ Plain X-ray or CT should be done as and when needed. During the secondary survey, it is important to elicit history with a focus on the details of

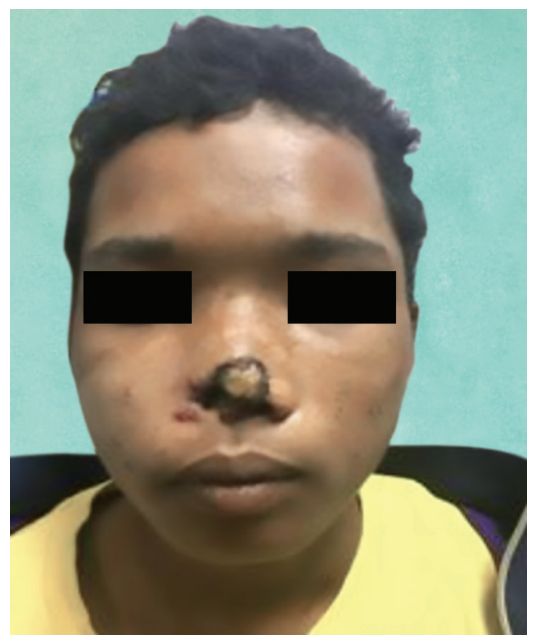

Fig. 4: After successful graft

the event as well as the tetanus vaccination status of the patient. A detailed head-to-toe examination is required, with special attention to specialized structures like the eyes, parotid ducts, facial nerve, and the nasolacrimal system. $^{2}$

The treatment of injuries caused by animals should take into account the following factors: soft tissue defects, neurovascular and bone injuries, as well as infection prevention. ${ }^{2,3}$ Generally, bite injuries on the face require meticulous wound debridement and generous irrigation, followed by immediate primary repair. ${ }^{2,3}$ These measures, in addition to prophylactic antibiotics, give good cosmetic results with minimum risk of infection. Psychiatric or social counseling may also be required, depending on the degree of psychological trauma. ${ }^{2}$

In case of a clinically uninfected bite wound, primary repair usually suffices. However, wounds which are at high risk of infection or already infected warrant delayed closure, with additional measures like local flap application or microvascular reimplantations where necessary. ${ }^{2}$ For maximum esthetic results, primary closure is definitely preferred, although doing so may sometimes run the risk of primary bacterial infections as well as lethal viral infections like rabies. ${ }^{2}$

Numerous aspects of antibiotic prophylaxis are controversial. This can be attributed to the fact that no single agent can cover all the bacteria responsible for wound infections. ${ }^{2,3}$ Also, a study has shown that antibiotic prophylaxis had no significant benefits unless the injury occurred at the hands. Nevertheless, co-amoxiclav appears to be the drug of choice for empirical prophylaxis. ${ }^{2}$ For this reason, our patient was started on IV co-amoxiclav. Other popular drugs include fluoroquinolones, azithromycin, and cotrimoxazole. The same drugs are used for the initial treatment of an infected wound, but the definitive antibiotic is dependent on the culture and sensitivity test results. ${ }^{2}$ 
In adults with animal-inflicted injuries, tetanus toxoid administration is not necessary unless the patient (a) has received his last dose of tetanus toxoid $>5$ years prior, (b) has insufficient tetanus vaccination, or (c) has an unknown tetanus immunization history. ${ }^{4}$ Nevertheless, we have empirically administered $0.5 \mathrm{~mL}$ of tetanus toxoid to this patient. Rabies prophylaxis comprises rabies immunoglobulins and rabies vaccines. The administration of the former is not needed if the patient has been previously vaccinated, but the latter should still be given. In case of the unclear history of rabies vaccination, the patient should be observed for 10 days, during which prophylaxis is given the moment the patient starts to show manifestations of the disease. ${ }^{2,5}$ As Muar is not a hotbed for rabies, and that the bite did not come from a cat or dog, we did not give rabies prophylaxis in this case.

Nasal injury repair warrants thorough preoperative planning. The amount of tissue loss and that of the remaining nasal skin should be estimated for debridement and closure. For this patient, the tissue loss was extensive (Fig. 2 ) and the repair warranted a full-thickness graft. The most common sites for harvesting such grafts include skin from the preauricular, postauricular, clavicle, and inner upper arm. This is because the skin in these areas provides better color matching for injuries at sun-exposed areas (e.g., face, torso, and extremities). ${ }^{6,7}$ A postauricular full thickness graft was performed, and the wound was successfully closed (Fig. 3). Unlike split-thickness grafts, full-thickness grafts provide better cosmetic outcomes, as evidenced in this case (Fig. 4). Another advantage of the latter over the former is that graft inclusion cysts do not occur, although it is the commonest complication in the former. ${ }^{6}$

Important postoperative measures include patient counseling, wound dressings and cleaning, as well as scar review. These ensure the best outcomes of the injury. ${ }^{8}$

\section{CONCLUSION}

In Malaysia, animal bites can result in very debilitating and mutilating injuries. Therefore, preventive measures should be taken before visiting tropical areas. Injury management is highly crucial at the regions with less soft tissue coverage, as gentle tissue handling and more advanced wound care may be needed. Proper wound care with irrigation, debridement, and skin-grafting results in better cosmetic outcomes and reduced scarring.

\section{REFERENCES}

1. Ingraneil D. Photographic Guide to Snakes and Other Reptiles of Borneo. New Holland; 2011.

2. Yadav AK, Jaisani MR, Pradhan L, et al. Animal Inflicted Maxillofacial Injuries: Treatment Modalities and Our Experience. J Maxillofacial Oral Surg 2016:1-9.

3. Fleisher GR. The management of bite wounds. N Engl J Med 1999;14:340.

4. Kretsinger K, Broder KR, Cortese MM, et al. Preventing tetanus, diphtheria, and pertussis among adults: use of tetanus toxoid, reduced diphtheria toxoid and acellular pertussis vaccine recommendations of the Advisory Committee on Immunization Practices (ACIP) and recommendation of ACIP, supported by the Healthcare Infection Control Practices Advisory Committee (HICPAC), for use of Tdap among health-care personnel. MMWR Recomm Rep 2006;55(RR-17): $1-37$.

5. Capellan O, Hollander JE. Management of lacerations in the emergency department. Emerg Med Clins North Am 2003;21(1):205-31.

6. Hexsel CL, Loosemore M, Goldberg LH, et al. Postauricular skin: an excellent donor site for split-thickness skin grafts for the head, neck, and upper chest. Dermatol Surg 2015;41(1): 48-52.

7. Robson MC, Krizek TJ. Predicting skin graft survival. J Trauma 1973;13(3):213-217.

8. Cavalcanti AL, Porto E, Dos Santos BF, Cavalcanti CL, Cavalcanti AF. Facial dog bite injuries in children: A case report. Int J Surg Case Rep 2017;41:57. 